\title{
Os scans e seu entorno subcultural-colaborativo
}

\section{The scans and their subcultural and collaborative environment}

\author{
Alexandre Honorio da Silva \\ Doutor pelo Programa de Pós-Graduação em Comunicação da Universidade Federal de Pernambuco (PPGCOM/UFPE), Mestre \\ em Ciências Sociais pelo Programa de Pós-Graduação em Ciências Sociais da Universidade Federal do Rio Grande do Norte \\ (PGCS/UFRN) e graduado em Comunicação Social, habilitação em Jornalismo, pela Universidade Federal do Rio Grande do Norte \\ (DECOM/UFRN). \\ <alexandre.honorio@ufpe.br>
}

\section{RESUMO}

Os scans são a expressão de uma prática subculturalcolaborativa de digitalização ilegal que ora dialoga com o domínio do fã de Histórias em Quadrinhos. O presente artigo procurará analisar tal prática e seus usuários através de dados obtidos de questionários aplicados entre 2012 e 2014 em comunidades dedicadas aos scans e da análise de dados coletados que procuram dar conta das rotinas de produção e distribuição de scans através de blogs, comunidades e fóruns dedicados a tal prática. A partir de tais dados consideramos que o scan emerge como artefato midiático-colaborativo e prática subcultural: ampliação imprevista de um artefato cultural e instância que mescla participação e colaboração enquanto elementos de envolvimento e pertença.

\begin{abstract}
The scans are the expression of a subculturalcollaborative practice of illegal scanning that deals with the fandom of Comics. This article will examine this practice and its users/members through data obtained between 2012 and 2014 in communities dedicated to scans and the analysis of the information collected seeking to explain how the production routines and distribution of scans works - how it is expressed through blogs, communities and forums dedicated to this practice. Through these data we suggest that the scan emerges as media-collaborative artifact and subcultural practice: a unforeseen expansion of a cultural artifact and instance that merges participation and collaboration as part of involvement and belonging.
\end{abstract}

Keywords: Scans. Collaborative Cultura. New Media.

\section{Introdução}

Este artigo pretende a análise quantitativo-qualitativa da prática subcultural e tecnoconvergente que se desenvolvera à margem do fandom ${ }^{1}$ de Histórias em Quadrinhos e que atende pelo nome de scan. Sugerimos que os scans e seu entorno subcultural se aproximam de outras formas colaborativas e culturais que se desenvolveram refletindo a expansão tecnológico-convergente

1 Por fandom compreendemos o domínio e a cultura de experimentação concebidas por fãs ao lidar com as formas culturais e com os sistemas de produção e distribuição que se projetam à margem dos compostos industriais-culturais (Fiske, 1992, p. 30) alterados pela influência e experiências compartilhadas por estes mesmos fãs a partir dos usos comunitários e colaborativos que têm feito das tecnologias do digital (Booth, p. 39). 
recente e representam a expressão dos humores de um objeto/artefato cultural em transição frente às práticas de seus interlocutores, consumidores e usuários.

Consideramos que aqueles envolvidos pelo entorno colaborativo compartilhado dos scans compreenderam que o lugar das HQs se expandira e que ora exprime algo mais que apenas um produto digitalizado: uma HQ vertida e disseminada como um scan é, para além de uma reprodução, um artefato ampliado, resignificado e que expressa uma construção midiáticocolaborativa², a qual, ainda, fundamenta um lugar de convívio compartilhado.

Para compormos tal análise recorremos sobretudo aos dados obtidos através de formulários aplicados entre 2012 e 2014 a usuários de blogs, comunidades e fóruns dedicados à produção e distribuição de scans e da reunião de outros dados que resultaram da observação participativa das rotinas de produção e distribuição destas mesmas instâncias dedicadas a esta prática midiático-colaborativa.

\section{Um perfil do usuário de scans?}

A reunião de dados que alicerça este artigo se deu em três momentos: o primeiro, entre os meses de junho e agosto de 2012, quando apresentamos um formulário contendo perguntas do tipo múltipla escolha respondido por 45 usuários dos fóruns SoQuadrinhos e Darkseid Club; o segundo, entre janeiro e abril de 2014, resultado da observação, acompanhamento e coleta de dados sobre as dinâmicas de produção de scans em blogs e fóruns dedicados a esta subcultura33; e o terceiro e último em julho de 2014 quando uma nova bateria de perguntas do tipo múltipla escolha, foi aplicada aos usuários do fórum SoQuadrinhos e respondida por 69 membros daquela comunidade.

Algumas das constatações que surgiram com a análise dos dados colhidos sugeriram a aproximação entre o domínio do fã de Histórias em Quadrinhos e as práticas e saberes que envolvem e alimentam os scans: percebemos que um scanner é um "fã ampliado" de HQs, uma vez que a ligação que mantém e compartilha com os scans, sua subcultura e seus espaços/ambientes resulta dos estímulos deste entorno à colaboração/participação - e estes, apesar de

2 Os scans expressariam algo do que Löwgren e Reimer sugerem quanto à transição de "uma forma cultural em particular através de uma prática colaborativa e mediada" que caracterizaria a ideia de ambos para mídia colaborativa (Löwgren; Reimer, 2013, p. 59).

3 Recorremos à noção de subcultura proposta por Hebdige (1979, p. 56), quando esta sugere os novos movimentos que resultam da apropriação periférica de elementos de uma forma cultural-industrial estabelecida por seus consumidores e esta mesma apropriação implica uma resposta crítica ou de resistência aos modos de tal indústria. 
assemelharem-se àquelas compartilhadas no seu fandom, são ampliadas pelo uso hipertecnológico dos meios.

A idade daqueles que participaram da pesquisa se manteve em equilíbrio entre as diferentes faixas etárias afeitas aos scans: aqueles com até 20 anos, corresponderam a cerca de 33\% dos entrevistados; usuários entre 21 e 30 anos, responderam por 40\%; e aqueles entre 31 e 40 anos, 23\% do total de entrevistados - enquanto usuários acima dos 40 anos corresponderam a 4\% dos respondentes.

Aqueles que se identificaram com os scans também se colocaram como afeitos às HQs e se disseram identificados e engajados (Duffett, 2013, p. 56) com seu domínio: cerca de $66 \%$ dos usuários de comunidades scans se disseram fãs de HQs e que tal culto se desenvolvera na infância (45\% dos respondentes). Outros usuários ( $31 \%$ deles), por sua vez, afirmaram ter se iniciado no consumo e culto de HQs somente na adolescência - e, dentre os que responderam à pesquisa, apenas $3 \%$ se disseram apresentados a esta mídia apenas na idade adulta.

- Perfil do Usuário de Grupos ou Comunidades de Scans - Idade

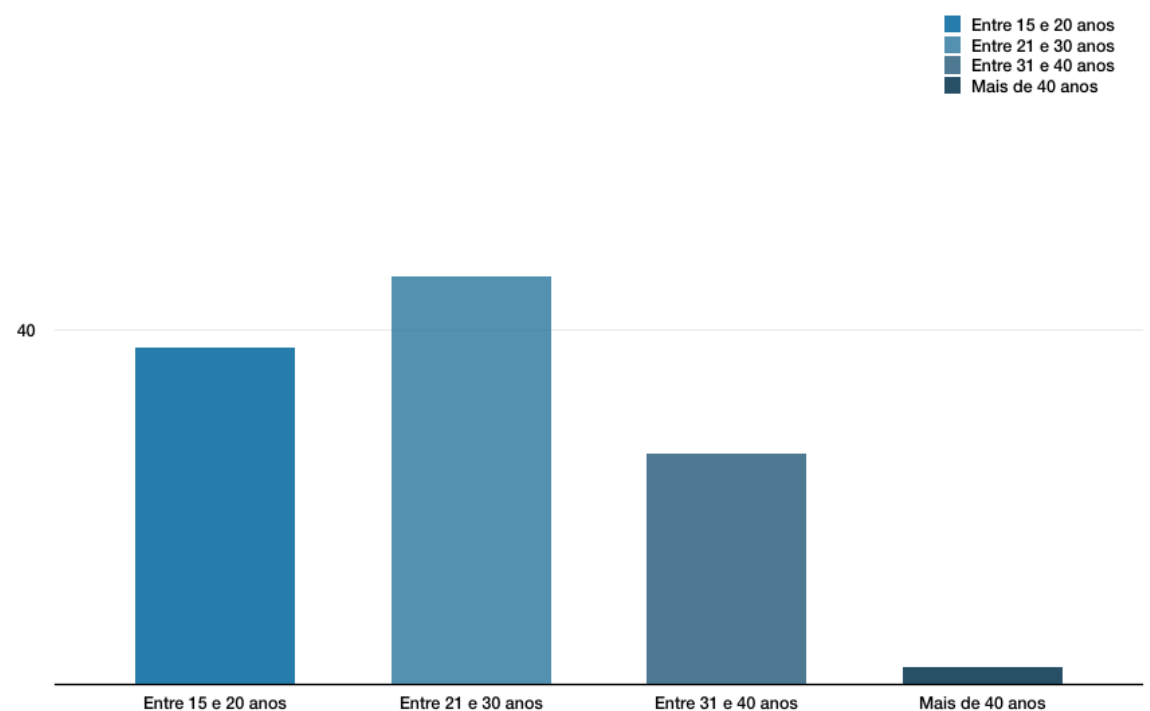

Fonte: $\mathrm{O}$ autor

É a proximidade dos scanners com o domínio comum à forma cultural com a qual dialoga que termina por alimentar sua atuação midiático-colaborativa e que surge através dos dados que analisamos até aqui: a relação entre idade e o momento de contato com o artefato objeto de culto (a partir do seu consumo, apreensão e expansão) quando da interação de seus atores/usuários com as 
diferentes comunidades dedicadas aos scans, mostram algo de uma vivência cultural reconfigurada, ampliada e adaptada deste artefato e que se expressa nas particularidades colaborativas deste.

Mas há, nas respostas providas através dos formulários aplicados, algo que sugere um certo tipo de usuário que demonstra não apenas seu apreço àquele artefato cultural que estima, mas à construção de uma identidade de grupo ligada a tal artefato - enraizada na ideia de uma percepção volátil de comunidade (Lipovetsky; Serroy, 2010, p. 98) transposta de uma experiência vivenciada em um domínio e adaptada com a possibilidade de expansão deste.

\section{Coleções, expansões, fandom...}

O foco daqueles que flertam com seus objetos de culto, seus limites e a compatibilidade/identificação individual deste cultuar (Jenkins, 1992) determina a dedicação para com um objeto/artefato ou como esta dedicação inscreve os seus: há um sentido que emerge com o culto e que resulta dos diferentes processos de apreensão e de curadoria dedicados aos objetos/ artefatos culturais - os quais consideram não só questões ligadas ao consumo, mas o potencial de apreensão, exibição, organização e manipulação (Jenkins; Ford; Green, 2013) que apresentam.

Duffett (2013) considera que aqueles que lidam com alguma forma ou artefato cultural/comunicacional cultivam e enredam um teia de afirmação e pertença tendo tais produtos como referenciais e é isto que, de certa maneira, dialoga com o domínio do fã: uma identificação apaixonada em relação aos fluxos e os diferentes níveis dispensados aos artefatos que atravessam tal noção de estima; algo de um domínio pessoal (Duffett, 2013), individual e, até, dos modos de experimentar que emergem desta convívio com tais produtos; um novo pensar, ser e viver (Lipovetsky; Serroy, 2010) que resulta da experiência compartilhada através de tal domínio.

Assim, se consideramosque olugar hipertecnológico recentecompreende a expansão/extensão de um fandom - em nosso caso, o das HQs - tal se dá porque este domínio se tornou uma instância ampliada possível à afirmação de um culto: ao apreço igualmente ampliado dos seus a algo que sempre esteve ligado não só à noção de individualidade, mas, ainda, ao pertencer que este convívio subcultural do fã fomenta.

\section{Domínios expandidos}

O engajamento daqueles envolvidos com os scans implica a combinação de saberes apreendidos pelo fã de HQs que se reconhece em um outro domínio 
de experimentação possível para seu objeto de culto: com os scans há um outro lugar onde a afirmação do sujeito-fã, sua estima e seu pertencer (Fiske, 1992) dialogam com outras demandas que ampliam/expandem a experimentação tanto de tal artefato original quanto de seu suporte.

Dos que responderam nossos questionários, $87 \%$ se disseram colecionadores de HQs e, além disso, implicados pelo domínio dos scans, porque o ato de colecionar e os interesses compartilhados (Booth, 2010) acompanham a experimentação do artefato quando tal se expande - já que a ambiência volátil de um artefato ampliado tecnologicamente representa um estímulo às possibilidades tecno-culturais que atravessam algo ressignificado e que brinda o sujeito com novas formas de experimentá-lo (Manovich, 2001).

É dizer que, dentre os que se definiram como colecionadores - por sua proximidade não apenas com o artefato que cultuam, mas com seu domínio compartilhado -, são eles os que flertam com um "outro" ambiente de experimentação: este, hipercultural e midiático-colaborativo onde, integrados a dinâmica de seus dispositivos, nós e redes, interagem e concebem uma versão ampliada de seu artefato de culto original, emulando não só as particularidades fundamentais deste, mas estabelecendo uma nova relação de estima dedicada a tal contraparte expandida.

Se considerarmos aqui que $57 \%$ dos se identificaram apenas como consumidores/leitores do que é produzido por comunidades scans, enquanto que $43 \%$ destes disseram participar ativamente de algum grupo ou envolvidos com algumas das etapas de produção/adaptação dos scans, temos uma perspectiva do equilíbrio ora existente em tais comunidades colaborativas.

No contexto das práticas e subculturas que flertam com a adaptação e distribuição não-autorizada de conteúdos - e, mais especificamente, entre os entusiastas dos sistemas $\mathrm{P}^{2} \mathrm{P}^{4}$ - há uma recorrência de atores empenhados na difusão destes e outros que tão somente consomem os conteúdos adaptados. No fim, seeders e leechers, agentes que fomentam, por exemplo, a subcultura dos torrents ${ }^{5}$ através das redes e sistemas P2P, não são tão somente atores, mas

4 Peer-to-Peer, ou simplesmente P2P, diz respeito as redes ou serviços em rede em que um mesmo terminal atua tanto como cliente quanto servidor. As redes P2P se popularizaram ao longo das duas últimas décadas notadamente com a ascensão do compartilhamento de arquivos como um dos momentos da expansão contemporânea da Internet.

5 Torrent é uma referência a um sistema de distribuição de dados através de redes $P 2 P$. Neste sistema, o torrent é referencia um arquivo a ser distribuído. Este, por sua vez, é fragmentado e distribuído através de outros usuários/terminais que também ancoram tal serviços. Seeders, dentro da terminologia dos torrents, é o detentor do arquivo distribuído; leechers são todos aqueles que, ainda que não tenham descarregado o arquivo distribuído pelos seeders, compartilha parte de tal arquivo contribuindo para a descentralização do processo de distribuição. 
componentes de uma dinâmica tecnológico-cultural comum que ora também alimenta o cerne da subcultura scan (Inside Scanlation, 2010).

Alguns distribuem, semeiam e lançam mais e mais artefatos ampliados à rede; outros apenas tiram aproveitam da abnegação dos primeiros. Há espaço para todos os credos e o domínio dos scans reflete tal espaço, visto que $87 \%$ dos usuários de comunidades scans entrevistados se identificam como colecionadores (a maioria, há pelo menos cinco anos).

Entretanto, a participação/colaboração em comunidades scans não é regra e não seria equivocado considerar que algo distinto de tal lógica se desenvolveria: entre os que consomem scans, poucos são os que realmente se envolvem com tal prática em suas diferentes etapas e muitos são os que apenas consomem o que usuários, grupos e fóruns produzem - mesmo com a constante renovação dos que exprimem uma participação comunitária mais ativa.

A expressão subcultural dos scans, assim como aquele que compele o fandom das HQs, evidencia um fenômeno social compartilhado (Duffett, 2013), expandido e que força o entrechoque de outras e diferentes instâncias e artefatos hipertecnológicos lidando ainda com as componentes agregadoras particulares a cada um de seus elementos (Lemos, 2010).

Mas o que se dá quando dois domínios se movem até um encontro inevitável? O que se dá quando um artefato cultural originário de um particular contexto midiático (este, analógico) busca e move-se na direção de outro (este, digital)? Teríamos uma expansão ou uma substituição? Ao menos do ponto de vista da relação expressa pelos usuários de comunidades scans, deveríamos considerar a primeira hipótese? A resposta curta!? Sim, uma vez que esta já se inscrevia na lógica do jogo e das extensões que caracterizam o âmbito das HQs enquanto meio (McLuhan, 2001, p. 194). Urge, entretanto, compreender que o scan atende a diferentes instâncias e que todas elas convergem para um domínio ampliado e compartilhado em torno de um meio em transição.

Para 49\% dos que responderam nosso questionário, a leitura de scan implica influência na decisão de adquirir um original impresso da mesma publicação e percebem aquela versão como espécie curatorial colaborativa. Já para 35\% dos entrevistados, os scans raramente exercem influência na tomada de decisão pelo equivalente impresso e mostra, assim, um equilíbrio entre os que optam pelo original e sua contraparte expandida.

Há, por sua vez, uma parcela dos usuários entrevistados que evidencia outro e crucial aspecto: $16 \%$ dos usuários pontuaram que sua decisão quanto a compra ou não de HQs impressas não sofre influência de seu recurso aos scans: as duas esferas convivem... 


\section{- Perfil do Usuário de Scans}

100

$$
\begin{aligned}
& \text { Apenas leitor } \\
& \text { Tradutor } \\
& \text { Revisor } \\
& \text { Diagramador } \\
& \text { Um pouco de cada atividade }
\end{aligned}
$$

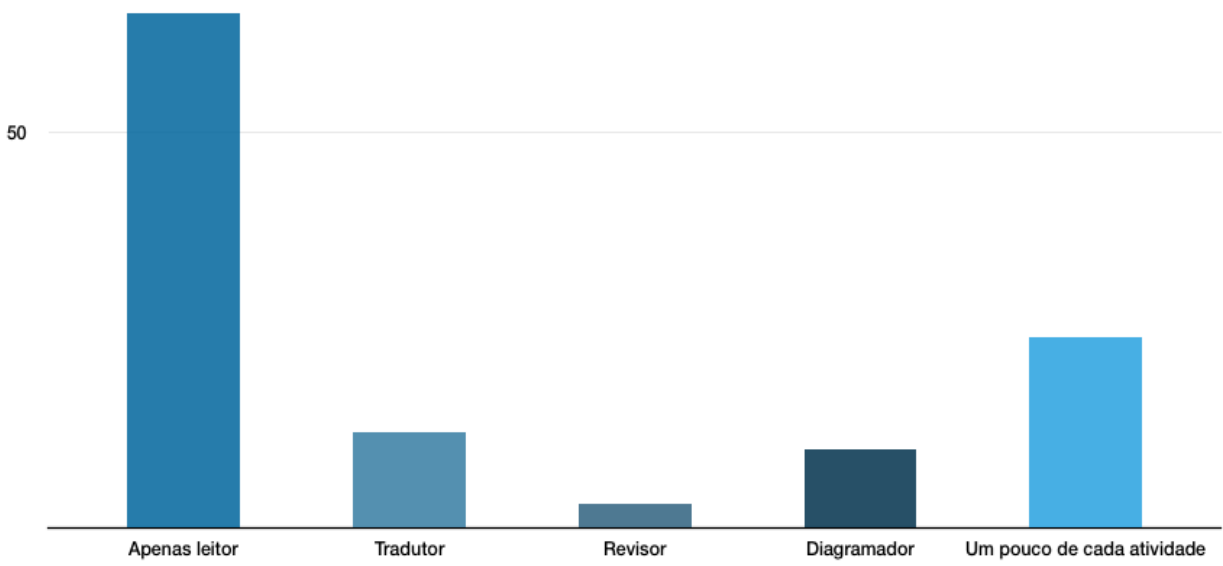

Fonte: $\mathrm{O}$ autor

\section{A complementaridade tática dos scans}

Jenkins (2013) pondera que, contemporaneamente, para lidar com o fluxo acelerado de conteúdos, aqueles que interagem com tais através da tênue linha que separa comunicação, tecnologia e cultura veem-se obrigados a acompanhar as dinâmicas de expansão que transformam seus artefatos midiáticos (Jenkins; Ford; Green, 2013).

Assim, na mesma medida em que a lógica de percepção e consumo de tais artefatos foi expandida, as possibilidades de experimentação e apropriação deles também o são - e os valores atribuídos/compartilhados por seus atores e as componentes sociais de intercâmbio destes (Jenkins; Ford; Green, 2013).

Uma das perguntas que formulamos àqueles que colaboraram com nosso questionário teve relação especial com o porquê de se recorrer aos scans: por que interagir e envolver-se com este entorno subcultural? Por que adotar e estimular uma prática colaborativa que, teoricamente, fragiliza a indústria que a nutre?

Com as respostas, percebemos que os usuários destas comunidades e demais instâncias dedicadas a tal, antes mesmo de considerar um scan a expansão de seu objeto de culto, o veem como um meio colaborativo: os scans se apresentam não só como um "artefato que emergiu da expansão de um meio", mas como um instrumento para experimentar uma forma cultural 
em transformação e que se equilibra em dois planos tecnológicos - e este é, provavelmente o mote que congrega muitos em torno desta prática.

No contexto curatorial, são duas as percepções as quais dialogam diretamente com a indústria que provê aos scans sua substância primordial neste contexto, as publicações e HQs - e como seus entusiastas a compreendem. Nas respostas, temos sugerimos como reflexo de uma certa"complementaridade tática" que - recorrendo ao conceito proposto por Certeau (2002, p. 38) - é exercida pelos usuários envolvidos por este artefato especialmente quando afirmam que a opção pelos scans decorre de questões como custo ou da necessidade de escolha de uma edição em particular dentre outras disponíveis.

Noventa e um por cento dos entrevistados disseram que primordialmente procuravam suplantar através dos scans as dificuldades para "chegar até" ou "interagir com" suas HQs favoritas: é dizer, de certa forma, que a opção pelos scans decorre não só de um culto anterior, mas, ainda, da percepção como etapa de experimentação deste mesmo algo cultuado - independentemente de seu suporte.

A natureza complementar e tática dos scans está no reconhecimento compartilhado por seus usuários/entusiastas de que, tanto quanto seu objeto expandido hipertecnologicamente, importa igualmente - talvez, mais - a ampliação de seu lugar de experimentação.

É o que compreendemos quando notamos que Scolari (2008) percebe algo desta expansão ao apontar três elementos necessários à análise de um meio em seu percurso interativo-participativo - especialmente quanto ao desafio aos modelos midiáticos tradicionais frente à ascensão desta mesma participação como motor dos sujeitos hipermediados: para ele, o entorno hipertecnológico é terreno em ebulição e ecossistema aberto à experimentação (Scolari, 2008, p. 200).

Compreende que tal experimentar, por sua vez, implica o esforço individual, que passa pela percepção e reconhecimento de uma atuação coletiva; e, por último, tem que considerar a complexidade das interações e do meio criativo-interativo onde seus sujeitos experimentam (Scolari, 2008).

Este esforço, no contexto pretendido por este artigo surge a partir de duas perspectivas: a que trata das práticas que usuários das comunidades scans desempenham na expansão/manutenção de sua subcultura e, de uma maneira ainda mais ampla, aquela que trata dos números expressos pelos scans e como estes se desenvolvem enquanto artefatos voltados à experimentação de um meio quando ampliado para além de seus limites originais. 
Apontamos que cerca de $43 \%$ dos que atuam com scans e suas instâncias se mostraram identificados com alguma etapa produtiva ligada aos scans - ou seja, envolvidos em alguma atividade ligada à produção/adaptação de HQs e sua disponibilidade em formato digital. Entretanto, mesmo entre os que se disseram envolvidos em alguma atividade considerada necessária à manutenção dos scans e sua subcultura, existem aquelas melhor assimiladas por seus usuários, grupos e comunidades.

Assim, enquanto os que se dispõem como tradutores respondem por cerca de $47 \%$ daqueles que colaboram com a produção/adaptação de scans, diagramadores somam 39\% dos usuários - a segunda atividade mais popular entre os usuários que participam mais ativamente das comunidades dedicadas a esta subcultura e uma das mais importantes. Revisores textuais e editores de imagens também integram tais frentes de colaboração, respondendo por 4\% dos usuários envolvidos em alguma atividade na cadeia de produção/ disseminação dos scans.

Os números nos levam a considerar que, como se dera com outras formas culturais igualmente influenciadas pelas expansões tecnoconvergentes recentes, a colaboração em torno das comunidades scans resulta do estabelecimento de posições; de indivíduos posicionados em relação ao que desenvolvem colaborativa e culturalmente a partir do artefato que cultuam - neste contexto, as HQs e a ampliação dos limites de tal meio.

No entanto, para termos uma relativa ideia do quanto o envolvimento dos usuários das comunidades e grupos de scanners exerce influência na manifestação desta forma subcultural e colaborativa representada, basta uma observação dos números demonstrados pela produção para concluirmos o quão significativa é a participação destes usuários.

\section{Processo adaptativo/produtivo colaborativo}

Entre janeiro e abril de 2014, ao longo de 90 dias consecutivos, acompanhamos a rotina de produção/distribuição de grupos e comunidades scans. Em tal período reunimos dados através dos blogs e fóruns dedicados aos scans e sua subcultura colaborativa e do fluxo produtivo/colaborativo destes, acompanhando a média mensal de HQs adaptadas e distribuídas como scans e as dinâmicas produtiva diária, semanal e mensal de diferentes grupos - o que 
possibilitou descobrir que no Brasil, para os scans, inexistem "quartas-feiras" (Wolk, 2011) ${ }^{6}$, mas estas continuam relevantes.

\section{As Principais Comunidades, Fóruns e Blogs} 400

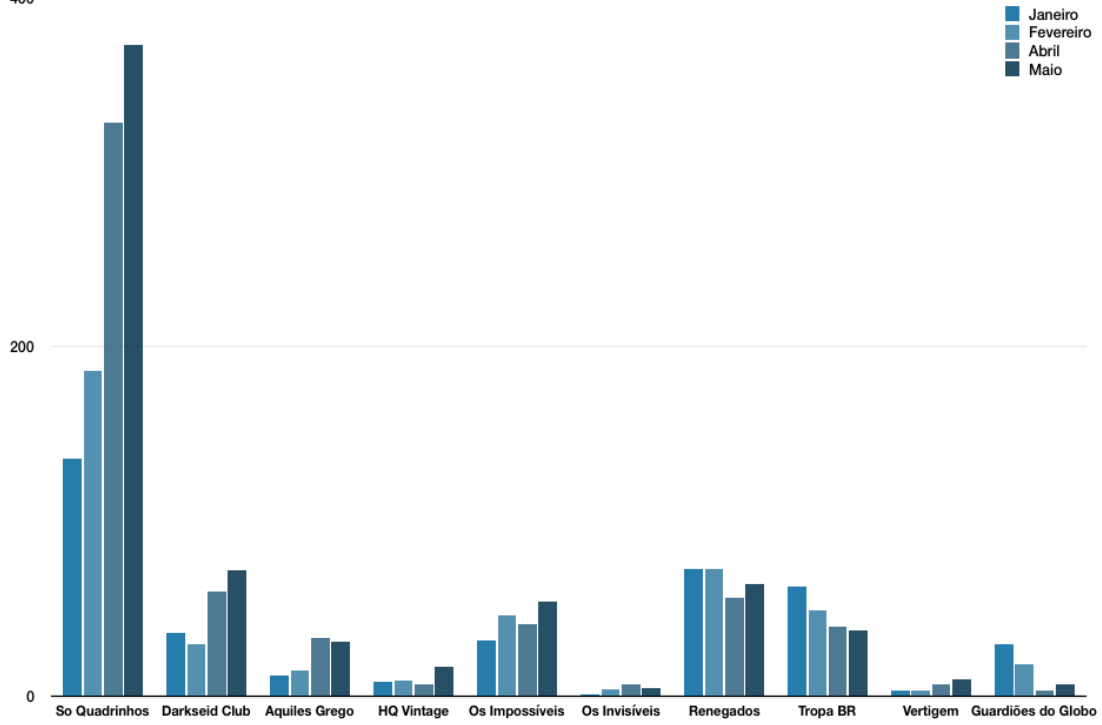

Fonte: $\mathrm{O}$ autor

Para chegarmos a esta constatação observamos/estabelecemos critérios na busca de retrato da lógica destas comunidades, blogs e fóruns - como excluir os que apenas a replicar scans produzidos por outros grupos ou sem maior expressão através desta subcultura. A partir destes chegamos/consideramos dez blogs/fóruns como representativas para os scans - e seu entorno subcultural. Blogs como Aquiles Grego (um dos principais articuladores da chamada iniciativa Era Marvel), Tropa BR, Renegados e Os Impossíveis e os fóruns SoQuadrinhos, Baú da Marvel e Darkseid Club se mostrariam os principais hubs ${ }^{7}$ dedicados aos scans e que alimentam seu entorno.

O acompanhamento da dinâmica de produção e distribuição dos scans mostrou que quase a totalidade dos blogs e fóruns que integram os arredores

6 As quartas-feiras são importantes para os scans: é neste dia da semana que tradicionalmente são lançadas as edições de novas Histórias em Quadrinhos no mercado norte-americano. Prova disso é que, neste porção do continente americano, a maioria das comunidades e grupos scans registram maior atividade neste dia da semana.

7 Um hub é um concentrador de informação. Quando projetamos uma rede de computadores, o hub é o dispositivo responsável por distribuir o sinal transmitido para diferentes terminais e vice-versa. No contexto das cultura dos scans, comunidades como as apresentadas atuam como hubs concentrando e retransmitindo a produção de seus diferentes grupos. A lógica dos hubs auxiliam as comunidades que fazem uso de redes $\mathrm{DC}++$, por exemplo. 
desta prática recorrem a serviços de armazenamento gratuito de arquivos como recurso ao compartilhamento do que é produzido por colaboradores e comunidades. A exceção a esta "regra" se deu em alguns fóruns e blogs como os da comunidade SoQuadrinhos e Mochileiro dos Quadrinhos - que, além de recorrerem a serviços/servidores disponíveis de armazenamento e compartilhamento de arquivos, mantêm ativos servidores $p 2 p$ do tipo $\mathrm{DC}++^{8}$ para que seus usuários registrados compartilhem scans remota e diretamente.

Esta adoção por fóruns e blogs de uma ou outra forma de armazenar e compartilhar scans reflete os usos dos saberes hipertecnológicos-culturais dos seus: Benkler (2006) afirma que a distribuição de quaisquer conteúdos através das redes lida com a relevância e credibilidade não apenas do que se produz, mas de quem o faz - inter-relacionando não só o que se distribui, mas o porquê deste fazer. Para Benkler, a adoção e disseminação de uma prática tecnoconvergente retém uma componente discursiva que interpela/interliga seus sujeitos em uma espiral de artefatos, artifícios e motivações (Benkler, 2006).

Com os dados percebemos que o cenário dos scans no Brasil reflete uma lógica particularmente curatorial-preservacionista das HQs: mais que artefatos ampliados de uma forma cultural, os scans são instrumentos que lidam com a manutenção de uma subcultura através de outra subcultura; representam o diálogo entre estes dois horizontes que lidam com a manutenção e disseminação desta mesma forma cultural.

Porém, como percebemos, os scans dependem da sintonia com uma indústria que, mesmo involuntariamente, os alimenta (Wolk, 2011) - sendo a prova de tal o que se dá semanalmente com blogs e fóruns, como SoQuadrinhos e Darkseid Club, que acompanham o fluxo produtivo desta indústria cultural e intensificam sua atuação posteriormente à atuação dela.

Existem duas razões aparentes para tal prática. Uma delas, como sugerimos há alguns parágrafos, diz respeito à regularidade. Tomemos como exemplo o que se dá com comunidades dedicadas à legendagem colaborativa de conteúdos audiovisuais: nelas, há uma clara janela de produção que vai da obtenção do conteúdo que sofrerá o processo de tradução/legendagem e a disponibilidade do resultado desta intervenção colaborativa para o restante da comunidade. Esta janela é um intervalo para que esta atuação colaborativa se desenvolva.

$8 D C++$ é um cliente $P 2 P$ que se utiliza do conceito direct connect característico dos serviços de Internet Relay Chat (IRC). O padrão surgiu em 2000 e desde então vem sendo empregado como alternativa para diferentes comunidades dedicadas ao compartilhamento de arquivos. 
Com os scans temos algo que guarda similaridades com o processo de tais comunidades, uma vez que a produção e distribuição de scans geralmente é concentrada nos dias posteriores ao lançamento de novas publicações no mercado estadunidense - aquele que alimenta as comunidades scans com maior frequência -, mas existem exceções expressas por comunidades e grupos donos com viés essencialmente preservacionista - caso dos blogs ligados à iniciativa Era Marvel e ao fórum Baú da Marvel.

Grupos dedicados à digitalização, restauração e ao percurso da cronologia de edições e publicações lançadas no país, observam os scans como um processo colaborativo que objetiva sobretudo suprir seu domínio de convívio/ experimentação com aquelas publicações nunca traduzidas - e que, vertidas ao digital, terminam cumprindo o papel de alimentar seu fandom. Do ponto específico do viés preservacionista, por exemplo, percebemos que grupos como Aquiles Grego, apesar de uma atuação aparentemente tímida quanto ao volume de produção, são donos de uma regularidade que impressiona quanto à disponibilização de scans.

\section{Algumas considerações...}

Os scans são tributários das mesmas transições que ora interpelam os planos da comunicação, cultura e tecnologia: uma mescla complexa que arremessa seus diferentes produtos em um entorno compartilhado e habitado por atores ávidos por participação e por uma afirmação possível através desta. Afirmamos que, recorrendo as apropriações e expansões concebidas colaborativamente em torno de um artefato cultural-comunicacional analógico - neste contexto, as HQs -, o entusiasta de tal artefato se fez reconhecível através das redes, dos dispositivos e, tomado pelos saberes acumulados em tal entorno, através das práticas que cultiva/difunde, procura com ampliar os modos como lida com seus diferentes objetos/artefatos de apreço (Duffett, 2013).

O comportamento daqueles que convivem e lidam com comunidades dedicadas aos scans - e o uso que estes fazem de tal entorno hipertecnológico, com seus dispositivos e saberes compartilhados - nos sugere algo de tal relação: dado que tais comunidades mantêm perfis em diferentes ambientes interativocomunicacionais, seus usuários também reconhecem e percebem em tais espaços oportunidades para interagir com outros usuários que compartilhem de suas mesmas predileções e valores - e este é um dado importante, já que $7 \%$ dos entrevistados afirmaram que o interesse pelas diferentes instâncias e comunidades scans não se deve essencialmente ao que estas produzem, mas decorre das oportunidades que têm de conhecer e interagir com outros usuários: 
estes percebem tais comunidades como nós de uma rede com particularidades específicas, ligadas a um nicho, vinculadas a um grupo de indivíduos em particular.

Esta interação com comunidades scans também ultrapassa os fóruns e blogs, uma vez que 53\% dos usuários entrevistados disseram acompanhar os grupos e comunidades preferencialmente através dos perfis mantidos por estes em diferentes plataformas de redes sociais.Voltamos assim à complementaridade que esta relação midiático-colaborativo com os scans encerra - assim como com outros artefatos deste gênero: perguntamos, portanto, sobre que dispositivos são utilizados no acesso a tais diferentes ambientes e que os usuários indicassem quais destes seriam os preferenciais quando do acesso e interação com comunidades scans ou em seu cotidiano com as redes.

No primeiro formulário que aplicamos, em meados de 2012, 57\% dos que o responderam disseram fazer uso preferencial do notebook quando da interação com as comunidades scans. Com a aplicação do segundo formulário, em 2014, este percentual cresceu três pontos, chegando aos $60 \%$ de utilização entre os diferentes dispositivos apontados. Com base nos dois questionários, computadores de mesa e notebooks se mostraram os dispositivos preferenciais dos usuários entrevistados quando de seu interagir com ambientes hipertecnológicos.

Outro ponto interessante também relacionado aos dispositivos utilizados pelos usuários disse especial respeito à expansão deste interagir: em 2012, 25\% dos entrevistados disseram recorrer a smartphones para acessar às redes e outros ambientes interativos. Na segunda consulta, em 2015, este percentual saltou para $43 \%$, mostrando que os dispositivos móveis se tornaram ainda mais populares entre os usuários de comunidades scans.

Uma perspectiva que sugere, por exemplo, que a transposição de um artefato ou forma cultural-comunicacional para uma nova esfera está atrelada aos usos que seus atores fazem do horizonte tecnológico-cultural próximo e que tal processo reflete a ansiedade daqueles que, interpelados pelos limites deste determinado artefato e pelas possibilidades do entorno hipertecnológico recentes, engendram formas de experimentar e sorver este artefato e as conversações com outros que ele termina por criar em sua expansão (Baym, 2010).

Se a cultura, a comunicação e o entorno hipertecnológico recentes recombinam diferentes formas midiático-culturais, estas são mescladas também através dos seus diferentes planos de experimentação; através, ainda, dos dispositivos e práticas tecnológico-convergentes disponíveis e, ao 
expandir um meio, a relação de seus atores com este também será ampliada: se uma hipertecnologia impele um artefato à expansão, seus consumidores/ produtores/prosumidores ${ }^{9}$ também são impelidos em tal movimento.

Este é o viés que nos leva a constatar, ainda a partir dos dados que reunimos para este artigo, que a manutenção de uma noção de envolvimento com um artefato ampliado resulta dos esforços daqueles em busca de espaços, práticas, recursos, suporte e de uma identificação que somente a noção de uma comunidade expandida parece oferecer.

Um scan é uma HQ e, ao mesmo tempo, a expansão dela: espécie de chave da comunidade expandida de experimentação que ela cria. Participando, colaborando ou simplesmente consumindo o que tal entorno produz/processa, o indivíduo ligado à quaisquer das etapas de produção/consumo de um scan se permite vincular não apenas ao "artefato-fim" representado por este novo momento expandido de uma mídia, mas, ainda, com seus processos e valores fundadores.

Os scans revelaram-se convites à experimentação, à expansão e ao pertencimento através de uma mídia bastante cara aos seus entusiastas. Mas não são todas a expansões hipertecnológico-midiáticas caras? E estas geram frutos, não!? No caso dos scans, sim...

\section{REFERÊNCIAS}

BAYM, Nancy K. Personal Connections in the Digital Age. EPub Version. Cambridge: Polity Press, 2010.

BENKLER, Yochai. The Wealth of Networks - How Social Production Transforms markets and freedom. London: Yale University Press, 2006.

BOOTH, Paul. Digital Fandom: New Media Studies. New York: Peter Lang, 2010.

DE CERTEAU, Michel. The Practice of Everyday Life. California: University Of California Press, 1988.

DUFFETT, Mark. Understanding Fandom: An Introduction to the Study of Media Fan Culture. EPub Version. New York: Bloomsbury, 2013.

9 O termo prossumidor foi cunhado por Alvin Toffler ainda na década de 1980 e buscava dar conta da redução da distância entre as figuras do produtor e do consumidor de determinado produtos. O professor da Universitat Pompeu Fabra, Carlos Alberto Scolari, recupera o conceito e o amplia ao sugerir que este prossumidor contemporâneo das redes não apenas produz/consome conteúdos, mas, com isso, busca estimular em outros a experiência que vivencia (SCOLARI, 2008, p. 248). 
FISKE, John. The Cultural Economy of Fandom. In: LEWIS, Lisa A. (Org.). The adoring audience: fan culture and popular media. Londres: Routledge, 1992. p. 30 49, 1992.

HEBDIGE, Dick. Subculture - The Meaning of Style. Londres: Routledge, 1979.

HIRATA, Tatiane; GUSHIKEN, Yugi. Scanlation: Reprodução e consumo subalterno de mangá na cibercultura. Líbero, Vol. 15, № 30, p. 127-138, 2012. Disponível em: <http://goo.gl/G4CV2e>. Acesso em: 12 jan. 2014.

INSIDE SCANLATION. Rise of the Release Trackers. EUA, 2010. Disponível em: $<\underline{\text { http:// }}$ goo.gl/UkgtGh>. Acesso em: 31 ago. 2014.

JENKINS, Henry. Textual Poachers:Television Fans and Participatory Culture. New York: Routledge, 1992.

; FORD, Sam; GREEN, Joshua. Spreadable media: creating value and meaning in a networked culture. EPub Version. New York: New York University, 2013.

LEMOS, André. Cibercultura: Tecnologia e Vida Social na Cultura Contemporânea. Porto Alegre: Editora Sulina, 2010.

LÖWGREN, Jonas; REIMER, Bo. Collaborative Media: Production, Consumption and Design Interventions. EPub Version. Massachusetts: MIT Press, 2013.

MANOVICH, Lev. The Language of New Media. Massachusetts: The Mit Press, 2001.

MCLUHAN, Marshall. Os Meios de Comunicação como Extensões do Homem. São Paulo: Editora Cultrix, 2001.

LIPOVETSKY, Gilles; SERROY, Jean. A Cultura-Mundo: Resposta a uma Sociedade Desorientada. Lisboa: Edições 70, 2010.

SCOLARI, Carlos. Hipermediaciones: Elementos para una Teoría de la Comunicación Digital Interactiva. Barcelona: Gedisa Editorial, 2008.

SILVA, Alexandre Honorio da. Scans e o entorno hipertecnológico e midiáticocolaborativo de um artefato cultural expandido. 2015. 193 f. Tese (Doutorado em Comunicação) - Programa de Pós-Graduação em Comunicação, Universidade de Pernambuco, Recife, 2015.

WERSHLER, Darren; SINERVO, Kalervo; \& TIEN, Shannon. A Network Archaeology of Unauthorized Comic Book Scans. AModern, 2013. Disponível em < gl/1o5Mu3 >. Acesso em: 22 dez. 2013.

WOLK, Douglas. The iPad Could Revolutionize the Comic Book Biz - or Destroy It. Wired. com. New York, Jul. 2011. Disponível em: <http://goo.gl/Rru742>. Acesso em: 16 jul. 2011. 


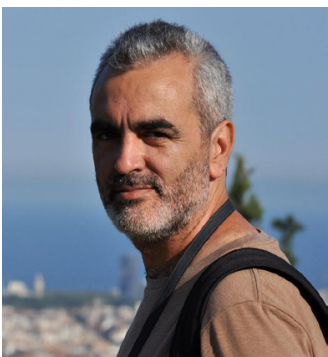

Recebido em: 5/8/2016

Aceito em: 8/8/2016

Endereço do autor:

Alexandre Honorio da Silva <alexandre.honorio@ufpe.br>

Programa de Pós-Graduação em Comunicação da Universidade Federal de Pernambuco (UFPE)

Av. Prof. Moraes Rego, 1235 - Cidade Universitária

50670-901 - Recife - Pernambuco - Brasil 